\title{
Use of technical hemp in the construction industry
}

\author{
Petra Nováková ${ }^{1, *}$ \\ ${ }^{1}$ The Institute of Technology and Businesses in Ceske Budejovice, Czech Republic
}

\begin{abstract}
Current requirements for building insulation are constantly increasing, not only in terms of the technical properties of the material used but also in terms of the environmental burden. This article focuses on the use of technical hemp in the building industry, describes individual products, its properties and uses. Part of the article is also the experience of realization and use of the building along with photographs.
\end{abstract}

\section{Introduction}

Cannabis is a plant with a rich history, a variety of uses in a number of industries, and a great potential for the future. We can learn about the possibilities of cannabis use in the field of construction from history. Today, the general greening trend determines this plant as an alternative building material.

In the past, cannabis was most often used for the production of ropes, netting, textiles, later in China for paper production. Hemp oil has been used in cosmetics and also in colour or light production. In construction, cannabis was used in conjunction with raw materials that could be harvested or produced directly at the site. It was often soil and matter-derived plants.

Cannabis was also part of the original half-timbered buildings in Alsace and other regions of Germany and France. It is also possible to see the detailed instructions on the production of hemp blocks of the year 1916 on the Internet [1].

\section{The three basic cannabis genera}

Rum Cannabis (Cannabis ruderalis Janisch.) is annual weed, growing freely on rum and dumps, without significant narcotic effects.

Indian Cannabis (Cannabis indica Lam.) is forbidden to grow for its high content of psychoactive substances called tetrahydrocannabinols (THC). The species has high narcotic effects because the THC content is greater than $0.3 \%$ in dry matter.

Cannabis, so called technical hemp (Cannabis sativa L.), is a thermophilic crop that is demanding for water, soil, nutrients, and agro-technology. It is a dioecious, or even a simple old fiber and cultural plant, growing in height from 2 to 6 meters. It suppresses the growth of weeds, has reclamation and anti-erosion influence, drains soil from poisonous substances and

\footnotetext{
* Corresponding author: petra.novakova@mail.vstecb.cz
} 
heavy metals. There is no need for pesticides or herbicides during growing, that are harmful to the environment.

It contains about $23 \%$ of the fibers and about $75 \%$ of the woody mass - the so-called shive. The growing period lasts 100 to 120 days, and at least $1 / 2$ hectares of woody material are grown on 1 hectare of growing area over 1 ha of forest growing for several decades [2].

\section{Technical hemp}

Technical cannabis is a versatile organic crop. From hemp can produce up to 25 thousand 100 percent recyclable products. The basic usable raw material is biomass (fiber, shive) and seed.

Stalk contains plant pulp - a wood part - suitable for biofuel production - pellets, briquettes, petrol, charcoal, methanol and electricity. In the world, cannabis raw materials are used in the food, chemical and textile industries, in medicine, cosmetics etc. In the Czech Republic, hemp seeds are mainly grown for the production of short fibers for technical use, nonwovens, paper and automotive, and for construction purposes.

It is also very important to use woody masses of shive - both for construction and especially for energy use in the form of bio-pellets and biobriquettes. Their heating value is $9 \%$ at a humidity of about $16.5-18 \mathrm{MJ} / \mathrm{kg}$. They are especially suitable for gasifying boilers for wood, fireplace stoves and fireplaces. These briquettes are pressed under high pressure without any binders or other harmful substances and are well usable in other types of stoves and solid fuel boilers [3].

Another product, cannabis seeds, contains $30-35 \%$ fatty acids with a high fat content. Cannabis oil obtained from cannabis pressing can be used as a motor fuel, for the production of paints and varnishes for natural wood preservation, or can be used in the food and canning industry. Cannabis seeds are used in the food industry, fishermen and bird breeders. Crops that remain after pressing the seeds are used as dietetic feed for livestock or as fuel [3].

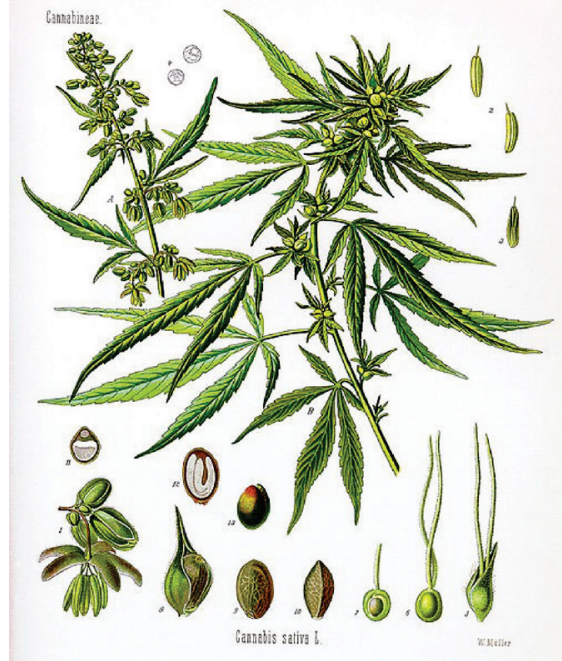

Fig. 1. Cannabis sativa [1].

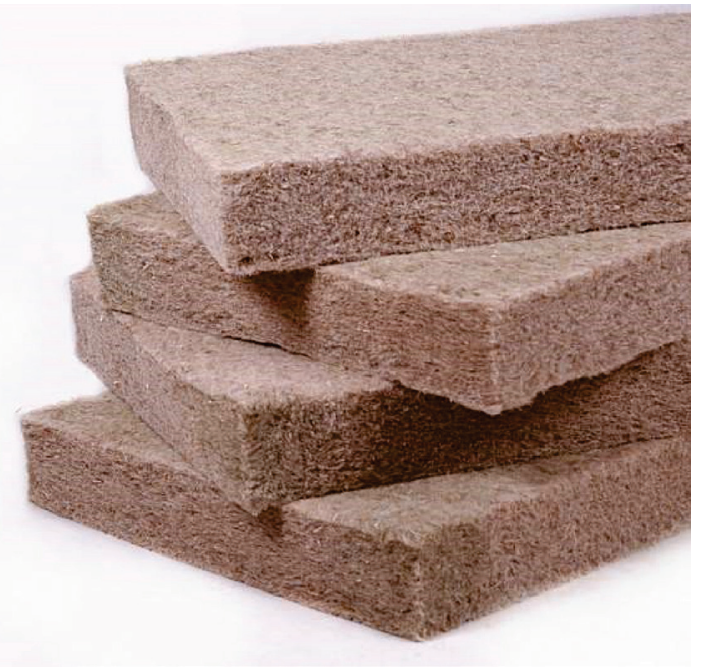

Fig. 2. Hemp bricks [4]. 


\section{The use of cannabis in the construction industry}

Like other natural materials, the use of cannabis is on the rise as well. Cannabis is a renewable strategic crop with a tradition of growing in our climatic conditions and high yields per hectare. Cannabis processing for cannabis and shive is done mechanically, without any polluting processes. Hemp fiber excels in its strength, durability and natural protection against pests. Threads and cannabis shavers have been embossed to reinforce the structure since the beginnings of construction, as well as grain husks, bran and animal fibers. Nowadays, hemp is used mainly in the building industry for the production of insulation, socalled cannabis concrete and varnishes [3].

\subsection{Hemp insulation}

This natural material provides a good microclimate with natural protection against mold, rot and pests and creates a healthy environment in the interior of the home. Thermal insulating and acoustic properties of cannabis are comparable to conventional insulations, but moisture resistance and capillary water drainage properties ensure stability even under conventional materials subject to destruction or significant reduction in isolating properties.

Soft hemp mats with a bulk density of $30-40 \mathrm{~kg} / \mathrm{m}^{3}$ are manufactured from purified hemp fiber by mixing with a binder, either bicomponent fiber based on polyester, or corn starch that is required in the order of $10 \%$. Against combustion, hemp insulation is treated with a retarder, such as edible soda. The final blend is shaped into an endless belt and fused together at $150{ }^{\circ} \mathrm{C}$, at the end being then cut to standard dimensions.

Insulation from hemp fiber has a thermal conductivity in the range of 0.38 to $0.4 \mathrm{~W} /\left(\mathrm{m}^{2} \mathrm{~K}\right)$, which is among the better products. With these parameters, hemp insulation is aligned with conventional insulation. But they also have other features that make them totally different from these products [1].

The hemp insulation is flexible enough because of the toughness of the hemp fiber, after a short time of compression, it returns to its original shape. This feature is particularly important when assembling when it is not possible to avoid squeezing the mat when inserting between the structural members. At the same time, the cannabis insulation maintains its shape for a long time, so that it does not settle and cause the cavities to develop in places where the insulation should be.

The specific heat capacity of cannabis is $\mathrm{c}=1600 \mathrm{~J} / \mathrm{K} . \mathrm{kg}$. That is, $1 \mathrm{~kg}$ of this insulation holds $1600 \mathrm{~J}$ at a temperature difference of $1{ }^{\circ} \mathrm{C}$. In practical terms, this means that if the temperature increases, hemp can receive heat. On the other hand, heat is released when the temperature drops. When comparing this parameter, we find that hemp insulation absorbs almost twice the amount of heat than mineral insulation, thus doubling the thermal comfort in the interior twice more effectively. This relatively high heat-storage capacity of hemp is comparable, for example, to wood. The composition of a low-energy wooden building using hemp thermal insulation then has a phase shift of 8 to 9 hours.

In order to eliminate moisture, the widest range of diffusion-open layers should be used in the outer edges of the perimeter structure, which, thanks to their breathability, easily draws moisture away. The diffusion resistance factor of hemp insulation has a value of $\mu=1.9$, which corresponds to a very permeable material and therefore optimal for this application.

In addition to high diffusion throughput, cannabis insulation has yet another advantage, namely the ability to redistribute moisture. In general, it is the ability to balance and transmit moisture through its entire volume, that is to say a kind of moisture conductivity. The moisture is transferred to the entire volume, resulting in a multiplicity of surface area for easy ventilation. Thanks to this, cannabis insulation is able to accommodate and cope with a large amount of moisture. Bulk density may increase up to $20 \%$ without reducing the efficiency 
of insulation. For comparison, mineral insulation results in loss of thermal insulation properties at $2 \%$ volume moisture.

Natural fibers are long, flexible and tough, so they are able to vibrate at the same frequency with sound waves. By their behavior, the intensity of the sound waves greatly weakens. Thanks to this, cannabis insulation is used as a high-quality acoustic insulation of sandwich composites for attenuation of airborne sound [1].

With all these benefits, cannabis insulation applications in the constructions and work processes are identical to conventional materials. Handling cannabis is pleasant, however, without the use of protective gloves or respirators, without the risk of skin or airway damage.

\subsection{Hemp concrete}

Lime-hemp building material is a revolutionary building and thermal insulation material that can be used to build the whole house, no bricks or other thermal insulation.
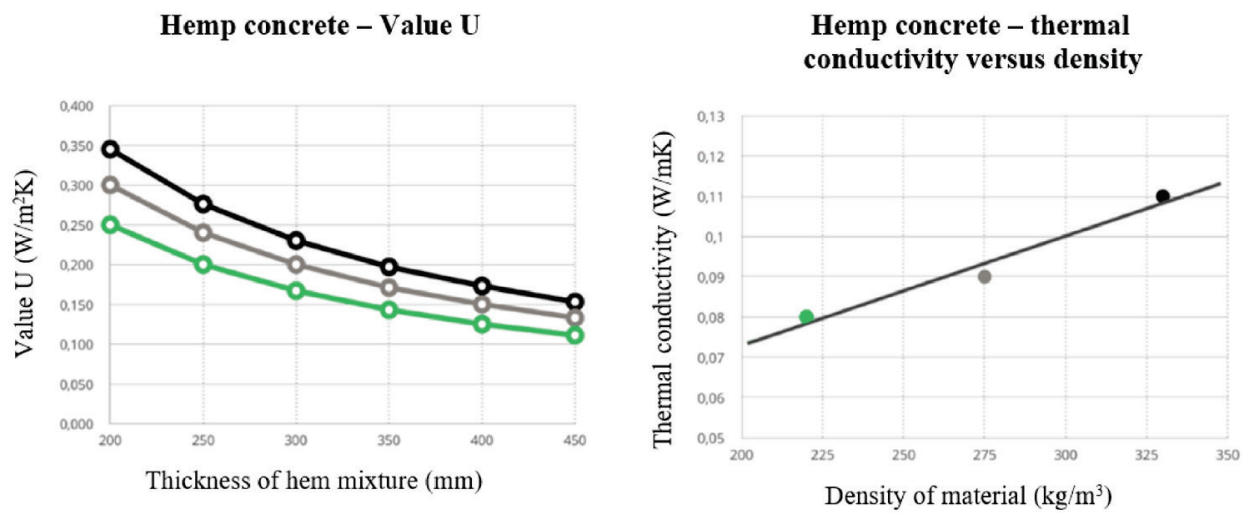

\begin{tabular}{|c|c|c|c|c|c|c|}
\hline MIXTURE & 200 & 250 & 300 & 350 & 400 & 450 \\
\hline Roof & 0.250 & 0.200 & 0.167 & 0.143 & 0.125 & 0.111 \\
\hline Walls & 0.300 & 0.240 & 0.200 & 0.171 & 0.150 & 0.133 \\
\hline Floor & 0.345 & 0.276 & 0.230 & 0.197 & 0.173 & 0.153 \\
\hline & \multicolumn{2}{|c|}{ Density $\left(\mathrm{kg} / \mathrm{m}^{3}\right)$} & \multicolumn{4}{|c|}{ Thermal conductivity $k(W / m . k)$} \\
\hline Roof & \multicolumn{2}{|l|}{220} & \multicolumn{4}{|c|}{0.08} \\
\hline Walls & \multicolumn{2}{|l|}{330} & \multicolumn{4}{|c|}{0.09} \\
\hline Floor & \multicolumn{2}{|l|}{375} & \multicolumn{4}{|c|}{0.11} \\
\hline
\end{tabular}

Fig. 3. Hemp concrete - value of heat transfer coefficient, thermal conductivity vs density [5].

Cannabis masonry, sometimes also hemp concrete, form a mixture of cannabis (hemp stem inside), hydraulic lime and water.

In practice, lime is obtained by limiting the calcined limestone and burning at temperatures above $825^{\circ} \mathrm{C}$. This process releases $\mathrm{CO} 2$ from the process. We are obtaining lime. By addition of water, the slaked (hydrated) lime becomes the heat. However, the classic Hydrated lime is not used, but the so-called Hydraulic lime, which is the one whose components react with water and thus promote a rapid increase in strength and partial water resistance at the time of the hemp-lime building substrate aging [4]. Hydraulic lime contains pozzolans, which include silicates. Lime is again transformed into limestone, respective "stone", due to absorption of atmospheric carbon dioxide. Materials covered by the lime are also transformed. The shive contains a large amount of silica, so contact with lime results in petrification - hardening to fossilization, making the material ideal for building. During the mineralization, the material drains from air the $\mathrm{CO} 2$ and purifies it. This material is ideal for 
construction. The material absorbs carbon dioxide out of the air during mineralization and thus cleans it [5].

The ratio of raw materials varies depending on whether it is a mixture on a wall, roof or floor. The resultant hemp lime concrete composite is lightweight (up to 7 times lighter than conventional concrete) and is therefore easy to work without even heavy technology. It is a recyclable material that offers high thermal and sound insulation.

Table 1. Hemp concrete mixtures according to use [5].

\begin{tabular}{|c|c|c|c|}
\hline \multicolumn{4}{|c|}{ Amount of material per $1 \mathrm{~m}^{3}$ of hemp concrete according to use } \\
\hline & Shive (kg) & Binder (kg) & Density $\left(\mathrm{kg} / \mathrm{m}^{3}\right)$ \\
\hline Roof & 110 & 110 & 220 \\
\hline Walls & 110 & 220 & 330 \\
\hline Floor & 100 & 275 & 375 \\
\hline Plaster & $200-250$ & $500-700$ & $700-950$ \\
\hline
\end{tabular}

Working with the building mix does not require special skill. When building the walls, the hemp concrete is most often squeezed into the formwork. When insulating the roof, it is rather looser, when the floor is finally wiped away, tightening. When plastering, it is classically cast, using a spray gun. For precise plasters it is worthwhile to sift and use only finer particles. Gloves and eyeglasses are good at work, as lime is slightly aggressive to earth.

Apart from the fact that hemp concrete is a universally functional and affordable building material, it is also environmentally friendly, its environmental balance is $\mathrm{A}+$.

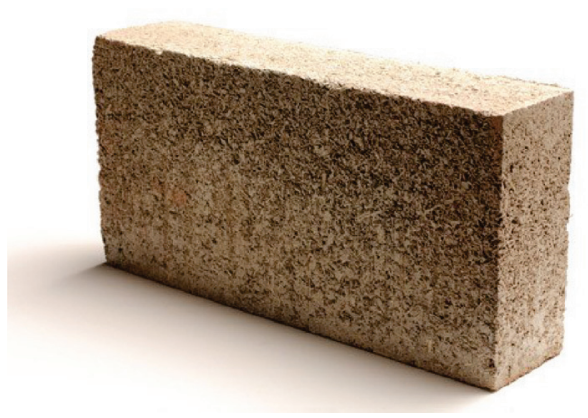

Fig. 4. Hemp concrete [4].

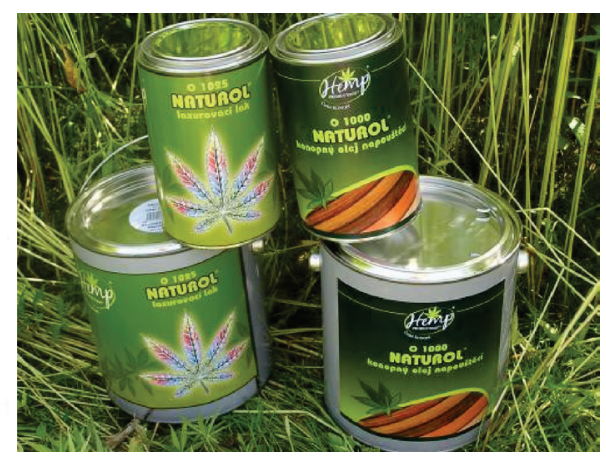

Fig. 5. Hemp oil and varnish [1].

\subsection{Hemp oils and varnishes}

Most natural constructions need more or less wood for their construction to protect them from the effects of mold and pests, outdoor elements also from the effects of weather. Very effective protective in these cases showed hemp coatings.

Hemp oil, like the whole plant, is very resistant to mold and repels the pest. It is a completely natural, biodegradable product, characterized by an increased resistance to soaking the wood with water. This oil also retains a water vapor permeable surface and thus can the wood breathe. As a general rule, the interior construction is sufficient to repaint pure cannabis oil, which, due to its pure natural composition, is also suitable for coatings of furniture, toys etc.

However, since this oil is not completely UV-resistant, it is necessary to treat the exterior elements with other means, such as a hemp lacqueric lacquer, which also contains mineral pigments to protect them from UV rays, and the wood is thus perfectly protected for many years [1]. 


\subsection{Honeycomb plaster}

Mixing cannabis, lime and sand creates a unique insulating plaster that can be applied up to a ten centimeter layer. In addition to working well and shaping it, it has the biggest advantage of breathing and regulating air humidity. The clay-hemp plaster looks natural, does not contain pollutants. The hemp plaster absorbs a lot of water and releases it gradually. Slower blasting does not cause it to crack.

\subsection{Hemp funiculs, ropes and strands}

The rope is made of $100 \%$ hemp without artificial impurities. Ropes are manufactured in different diameters and have high strength. They are used in joints for installing windows and frames, sealing fillers in frames, sealing expansion joints, sealing dilatation joints, building and repairing houses, bridges, tunnels, wooden cottages, etc.

\subsection{Other building materials of cannabis}

In ground and water construction, both classical and minerally enriched cannabis geotextiles can be used. Cannabis plastics are environmentally friendly. For example, they do not emit harshly harmful phthalates and do not cause allergic reactions. Recent research has shown that these plastics exhibit greater flexibility and resistance to pressure than synthetic plastics. It is possible to produce the installation materials needed for building a house, which are otherwise usually made of PVC, such as pipes and knees.

Other applications include unburnt bricks molded from cannabis and clay. Because of the insulating properties of cannabis, clay-hemp masonry does not require any additional insulation layer. However, bricks can not be used to build load-bearing walls (three-quarters of bricks make clay, $25 \%$ cannabis).

Thanks to the use of cannabis seals, for example, it is possible to avoid frequent damage caused by condensed water on roof windows in the area of the frame. Hemp felt impregnated with 3-5\% sodium carbonate can, for example, bind moisture out of the surrounding air and then gradually evaporate it. This protects the interior from moisture fluctuations [1].

\section{Experience in the implementation and during using of the building}

When constructing hemp concrete, it must be remembered that it is a natural material, ie. without different chemical accelerators or other additives. The investor has to expect a longer drying time, approximately 6 - 8 weeks depending on the weather.

According to the designer, the object can be based on spread footing foundation or on slab-on-grade foundation. The supporting structure usually consists of a wooden structure. All the technical equipment of the buildings (water, waste, electricity, etc.) are prepared before the application of hemp concrete. The application of cannabis is then applied by spraying or more often into the formwork. A great mover for mixing a hemp concrete mix is a panmixer without which construction would take much longer, because its volume is more than three times larger than a conventional mixer. The mixture poured into the formwork hardens within a few hours, so that after approximately twelve hours the formwork can be removed and moved further, and the mixture is automatically resistant to pests, molds and fire. In the realization of the masonry, one has to do in one step not only the masonry, but also the insulation and it can be said, for the most part, also the surface treatment, which is a great advantage. 
When using hemp concrete for thermal insulation of the roof, the material isolates not only in winter but also against overheating during the summer. In addition, no vapor barrier or vapor barrier films are usually used in the application. Hemp concrete will handle moisture [4].

Classical lime plasters, hemp lime plasters, clay plaster, wooden cladding and others can be used as a surface finish. It is important to ensure good water vapor diffusion. Hemp concrete should not be used in the construction below ground level.

The use of hemp insulation usually requires the same procedures as for mineral insulation.

The ready-made construction is a reward for the investor because the plants, the animals and he feels good in it, do not breathe the spores of molds and other products resulting from excessively moisture-free. Natural materials additionally support the preservation of so much for our health of important negative ions in the air.

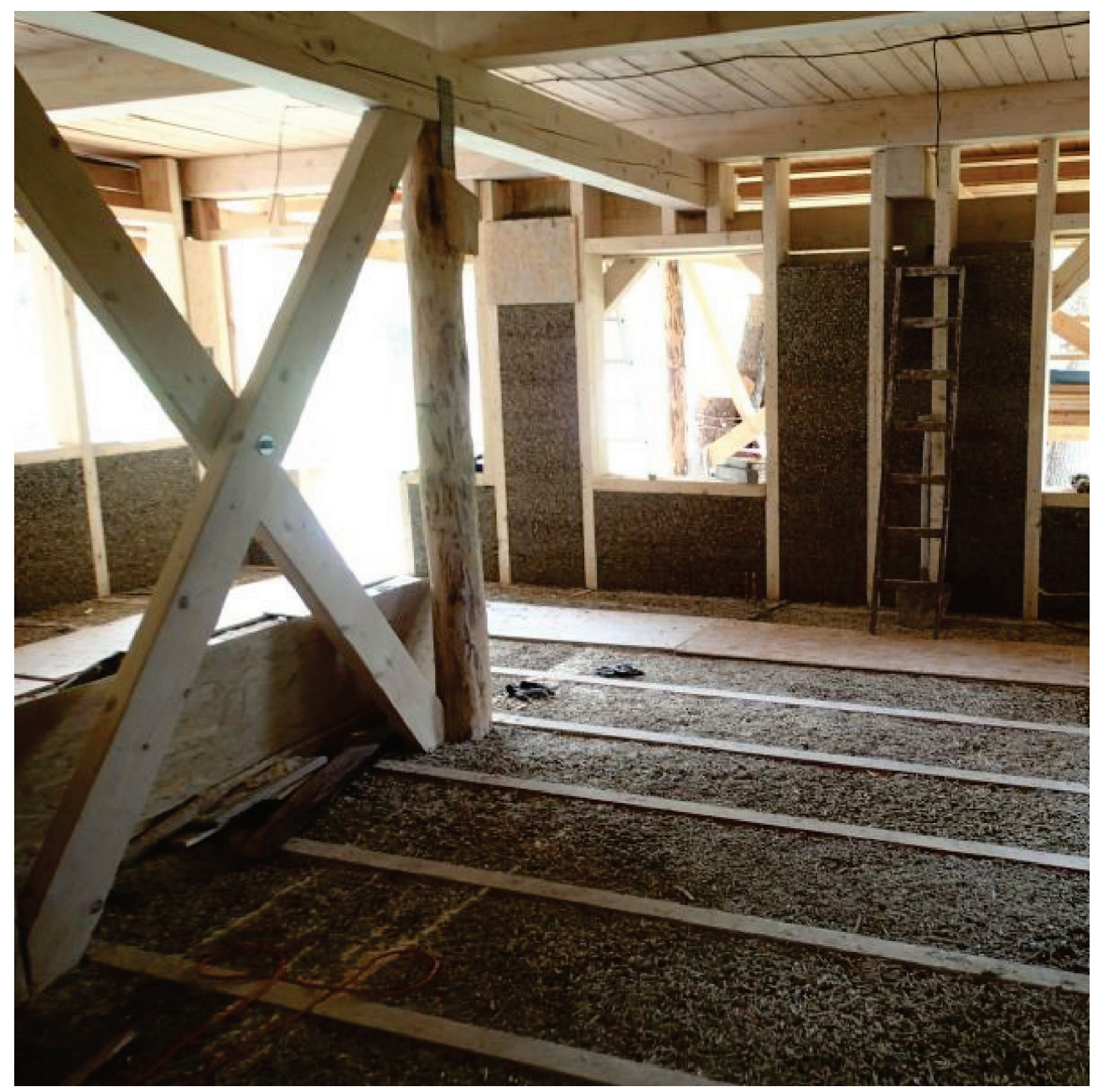

Fig. 6. Hemp concrete walls and floors [4]. 


\section{Conclusion}

Many building materials with excellent properties are used in the building industry. However, their production has direct or indirect impacts on the environment, as well as products from these materials. For example, stone melts of $1600{ }^{\circ} \mathrm{C}$ are required to form mineral-based fibers; for comparison: hemp mats are thermally stabilized at a temperature of 150 to $160^{\circ} \mathrm{C}$. A further comparison can be the amount of production emissions from the processing of petroleum products for the production of synthetic materials, as opposed to the fragrant work of drying and "breaking" of plant raw materials.

Cannabis as a fast-growing annual herb in its growth is highly absorbed by $\mathrm{CO} 2$. In the processing and extraction of building materials, $\mathrm{CO} 2$ is produced on the contrary. This also occurs in the case of lime. However, lime alone in its reaction, when mixed with water (that is, at the time of application itself), $\mathrm{CO} 2$ again in the air again massively absorbs. The result is a passive $\mathrm{CO} 2$ balance using cannabis concrete, which derives from both binder and cannabis. For an idea: a detached house with a floor area of $100 \mathrm{~m}^{2}$ with $500 \mathrm{~mm}$ hemp wall thickness, contains about $120 \mathrm{~m}^{3}$ of hemp concrete. Captured about 13 tons of $\mathrm{CO} 2$ will be captured [4].

Cannabis is an excellent alternative to wood. This even surpasses in some respects. Building materials from it are several times more flexible and healthier. Cannabis isolates greatly, breathes and does not attract molds. The fact that it grows very fast for cannabis also speaks. The time for obtaining good wood material is several times longer. It takes 4 months to grow the material. We do not have to worry about allergic reactions - they do not evoke any.

If we are looking for environmentally friendly building material, our health and excellent properties, cannabis use is a possible option.

\section{References}

1. M. Urbancová, Konopi ve stavebnictví, Czech Republic (2016). Available on https://www.asb-portal.cz/stavebnictvi/materialy-a-vyrobky/tepelne-izolace/vyuzitikonopi-ve-stavebnictvi

2. W. Stanwix, A. Sparrow, The Hempcrete book: Designing and building with hemp-lime (2014)

3. S. Allin, Building with hemp (2012)

4. P. Majringer, Konopný-beton, Czech Republic (2004). Available on http://www.konopny-beton.cz/

5. M. Šedivý, Konopné stavby, Czech Republic, Available from : http://konopnestavby.cz 